\title{
Infant Survival Among Free-Living Bonnet Macaques (Macaca radiata) in South India
}

\author{
Małgorzata E. Arlet ${ }^{1}$ (D) Krishna N. Balasubramaniam ${ }^{2} \cdot$ Rajarshi Saha $^{1} \cdot$ \\ Brianne Beisner ${ }^{2,3}$. Pascal R. Marty ${ }^{2}$ - Stefano S. K. Kaburu ${ }^{4}$. \\ Eliza Bliss-Moreau ${ }^{5}$ • Ants Kaasik ${ }^{6}$. Ullasa Kodandaramaiah ${ }^{7}$. \\ Brenda McCowan ${ }^{2,3}$
}

Received: 29 October 2020 / Accepted: 6 January 2021 / Published online: 2 March 2021

(C) The Author(s) 2021

\begin{abstract}
Female reproductive success depends to a large extent on infants' ability to survive to maturity. While most studies of female reproductive success have focused on the effects of individuals' sociodemographic factors (e.g., age/parity, dominance rank) on offspring survival among wild primates living in less disturbed habitats, little research has focused on offspring survival in urban or periurban animals. Here we investigated sociodemographic and anthropogenic determinants of infant survival (up to $1 \mathrm{yr}$ of age) in free-ranging bonnet macaques (Macaca radiata) living in a periurban environment in Southern India. We conducted the study from November 2016 to May 2018, on two groups of bonnet macaques at the Thenmala tourist site in the state of Kerala. Fifty infants were born across two birth seasons. Of these infants, $29.2 \%$ died or disappeared in 2017 and $26.9 \%$ died or disappeared in 2018. We found that infant survival was strongly influenced by the mother's parity: infants of experienced mothers had a better chance of survival than those of first-time mothers. We also found that male infants were more likely to die than female infants. However, we found no effects of mothers' dominance rank, or of frequency of mothers' interactions with humans and time spent foraging on anthropogenic food, on infant survival. Our results, consistent with findings from other wild primate species, show that even in challenging human-impacted environments, experienced bonnet macaque mothers have greater success than inexperienced ones.
\end{abstract}

Keywords Anthropogenic factors · Bonnet macaques · Dominance rank · Infant mortality · Infant sex $\cdot$ Parity

Handling Editor: Joanna Setchell

Małgorzata E. Arlet

malarl@amu.edu.pl

Extended author information available on the last page of the article 


\section{Introduction}

Infant survival is a major contributor to animal fitness, which makes the causal factors that affect infant survival in wild animals such as primates of interest to both evolutionary and conservation biologists. Broadly, the likelihood of primates surviving beyond infancy is determined by differential maternal investment and the quality of maternal care (van Noordwijk 2012). Maternal behavior may, in turn, depend on several factors, primarily access to food resources (e.g., Lee 1987), but also the mother's experience in raising offspring, her age, and her social status (Abello and Colell 2006; Harcourt 1987; Pusey et al. 1997; Robbins et al. 2007; Wasser et al. 2004). Thus, infant survival may depend on many factors that are attributable to individual animals (e.g., mothers' age, parity, sex of the infant), their social environment (e.g., mothers' dominance status), and their ecological environment (e.g., access to food resources, predation, human impact on the natural environment).

Female parity is often correlated with age, as first-time (primiparous) females are usually younger animals than those with a good deal of maternal experience. As primiparous females are often still growing, they must allocate their energy to both their offspring's growth and their own growth (Bercovitch et al. 1998; Setchell et al. 2002). Consequently, younger mothers may not be able to invest sufficiently in their offspring to keep them alive. Moreover, as the reproduction rate of older multiparous females is lower, they are more likely than younger mothers to invest care and protection in their offspring (e.g., Arlet et al. 2014, 2019), which may in turn lead to higher infant survival. Indeed, a literature review found that younger mothers' infants were more likely to die than those of older mothers in 15 of 21 primate species (Pusey 2012). In female rhesus macaques (Macaca mulatta), age-related change in milk quality (or yield) may be responsible for differences in infant size (Hinde and Capitanio 2010). As females become older and stop growing, the energy available in their milk increases (Hinde and Capitanio 2010). Consistent with this finding is that first-born yellow baboon (Papio cynocephalus) infants have lower body mass than later-born infants, which may suggest low maternal investment by mothers that are still growing (Altmann and Alberts 2005).

In many primates, male infants require more maternal investment than female infants (e.g., chimpanzees, Pan troglodytes: Nishida et al. 2003; mountain gorillas, Gorilla beringei: Robbins et al. 2007; Hanuman langurs, Semnopithecus entellus: Ostner et al. 2005; rhesus macaques: Bercovitch et al. 2000; Dettmer et al. 2016). Greater maternal investment is suggested by longer interbirth intervals following the birth of sons (Bercovitch and Berard 1993; Bercovitch et al. 2000; Ostner et al. 2005; Robbins et al. 2007), longer lactational periods with sons (Ostner et al. 2005), greater body mass in sons (Bercovitch et al. 2000; Hinde 2009), and higher quality milk for sons (Hinde 2007), compared to daughters. Therefore, greater male mortality in infancy has been related to male infants needing more maternal investment than female infants, but not receiving enough maternal investment to thrive (Drevenstedt et al. 2008; Hinde 2007). In rhesus macaques, for instance, the overall energy available in young mothers' milk is lower than in multiparous females' milk, and therefore primiparous females are often unable to sustain that investment in sons (Hinde 2007).

Prior experience of infant care can also have a positive impact on a mother's own infant survival (chimpanzee, Pan troglodytes: Pusey 2012; vervets, Chlorocebus 
pygerythrus: Fairbanks 1990; lion tamarins, Leontopithecus spp.: French et al. 1996; Japanese macaques, Macaca fuscata: Schino and Troisi 2005; great apes: Abello and Colell 2006). Females that survive long enough to have multiple offspring gain experience with care of their own infants, which may improve infant survival and thus reproductive success (e.g., Arlet et al. 2019). Another way to gain experience with infant care is alloparenting, which may enhance individual animals' own parenting skills (Silk 1999). Young females usually handle infants more clumsily and become more skilled with age and experience (Hrdy 1976; Meaney et al. 1990; Silk 1990). Moreover, help from others enhances the likelihood that a young female will raise her first offspring successfully (Fairbanks 1990). However, rough handling by group conspecifics (Kleindorfer and Wasser 2004; Isbell et al. 2009), including subadult and adult females with no infants, may lead to infant death. This may explain why, among bonnet macaques, for example, mothers are reluctant to allow their offspring to be handled, although females of all ages are strongly attracted to infants (Silk 1990; Simonds 1974).

Female dominance rank may impact a female's energetic balance and behavior, and thereby influence the survival of her offspring. Higher-ranking females may be able to provide greater maternal investment than lower-ranking females, achieving higher infant survival (van Noordwijk and van Schaik 1987, 1999). As mothers vary in their quality, they invest differential amounts of energy in infants (Garcia et al. 2009). Infants of high-ranking female olive baboons (Papio anubis) and chimpanzees at Gombe (Tanzania) tend to have higher survival than infants of low-ranking females (Packer et al. 1995; Pusey et al. 1997). Dominance rank also influences aggression directed toward the mother and her infant. In Japanese macaques, for instance, lowranking mothers receive twice as much aggression as high-ranking mothers and are therefore more prone to abandoning their infants (Schino and Troisi 2005) and that, in consequence, leads to the infants' death.

Aside from demographic attributes and social factors, ecological factors such as females' access to resources and exposure to predation may affect infant survival (Sterck et al. 1997). While most studies in this regard have focused on wild, relatively unperturbed primate populations, we know little about how urban ecology may impact infant survival among primates living in human-impacted or anthropogenic environments. Anthropogenic habitats can impose challenging, stressful living conditions on wild primates (Fuentes 2012; McKinney 2015), causing individuals to be more vigilant in order to avoid antagonistic, stressful interactions with humans (Balasubramaniam et al. 2020a; Kaburu et al. 2019a, b; Marechal et al. 2011; Marty et al. 2019a), which may negatively impact reproductive success. Furthermore, primates in anthropogenic habitats, particularly in urban or periurban environments, may change their foraging strategies to rely more on human-provisioned food, which is generally more predictable and of higher calorific value than natural food (Marty et al. 2019b; McLennan and Ganzhorn 2017; Oro et al. 2013; Riley et al. 2013 ). Access to human-provisioned or anthropogenic food may also have consequences for reproductive success and has been previously linked to shorter interbirth intervals and lower infant mortality in primates (Jaman and Huffman 2013; Kurita et al. 2008; Warren et al. 2011). However, anthropogenic food has also been associated with health-related costs (e.g., Japanese macaques, Macaca fuscata: Sugiyama et al. 2014; olive baboons: Sapolsky and Share 2004), and therefore may negatively (rather than positively) impact infant survival over longer periods. 
Bonnet macaques (Macaca radiata) are well suited for studying the effects of maternal demographic and social attributes on infant survival, in the relative absence of alloparenting (Rahaman and Parthasarathy 1969; Silk 1990; Simonds 1974). They predominantly live in multimale, multifemale groups, in which females are philopatric and males tend to disperse when they reach sexual maturity (Singh et al. 1984). Females form stable and matrilineally heritable dominance ranks (Silk et al. 1981a). They generally live in seasonal environments (dry and wet season) in Southern India, and most females within a group resume cycling synchronously and give birth during the dry season (typically January-April), just before the monsoon (Rahaman and Parthasarathy 1969; Singha 2001). After the infant is born, the mother-infant relationship continues for $c a$. 6-10mo and is strongest during the first few weeks of life (Nathan and Kaufman 1972; Rahaman and Parthasarathy 1969; Simonds 1965; Singh et al. 1980). Bonnet macaque mothers are often protective of their infants during this period, and allomothering is rare (Rahaman and Parthasarathy 1969; Simonds 1974).

Bonnet macaques are also a suitable model species to assess the impact of urban ecology, specifically anthropogenic factors, on infant survival. Many populations of this species inhabit roadsides, temples, villages, agricultural fields, and small towns of Southern India, where they live close to humans; a relatively smaller portion of these macaque populations inhabit forests and protected areas (Kumara et al. 2010; Sinha 2013; Sinha and Mukhopadhyay 2013). Over the years, the habitat of bonnet macaques in India has reduced substantially due to agricultural expansion, urbanization, and road development (Sinha 2013; Sinha and Mukhopadhyay 2013). At the same time, the probability of mortality due to factors such as collision with vehicles and electrocution has increased (Erinjery et al. 2017). Such anthropogenic factors have been implicated in a drastic population decline of bonnet macaques in recent years (Erinjery et al. 2017; Kumar et al. 2011; Singh and Rao 2004; Singh et al. 2011).

Here we assessed the social, demographic, and anthropogenic determinants of infant survival in wild bonnet macaques living in periurban environments in Southern India. We predicted that if prior experience of maternal care positively impacts infant survival among bonnet macaques, then infant survival will be greater among older and/or multiparous mothers compared to among younger, primiparous mothers. If high dominance rank is associated with increased reproductive success, then dominance rank will show a positive effect on infant survival. If mothers tend to be more protective of their daughters than their sons, which are also likely to be more mobile or exploratory in their behavior, then female infants would be more likely to survive compared to male infants. Finally, if exposure to anthropogenic environments is stressful and imposes costs on primates, then we predicted that infant survival will be negatively associated with the mothers' frequencies of interactions with humans. In contrast, if access to anthropogenic foods that are generally higher in calorific value than natural foods offset the costs of interacting with humans, then females' tendencies to forage on anthropogenic foods will positively (rather than negatively) impact infant survival.

\section{Methods}

\section{Study Area and Subjects}

We conducted the study between November 2016 and May 2018 at Thenmala dam and ecotourism recreational area, in Kerala, Southern India $\left(8.9^{\circ} \mathrm{N}, 77^{\circ} \mathrm{E}\right)$. Aside from a few 
small forest patches, the area covered three villages, forest offices, and an ecotourism center. The area is home to several groups of bonnet macaques. We focused on two groups that were different in size, whose ranges partially overlapped with each other and covered forest patches and anthropogenic landscapes. During the study period, the home range of the large group (LG; Table I) was $c a .0 .32 \mathrm{~km}^{2}$. The home range of the small group (SG) was ca. $0.16 \mathrm{~km}^{2}$ (Balasubramaniam et al. 2020a).

The subjects of this study were all females with infants: in 2017, we observed 26 mother-infant pairs, and in 2018 we observed 24 mother-infant pairs. To determine age classes, we adapted the approach originally proposed by Strum and Western (1982) for olive baboons. Specifically, we categorized females into the following three categories based on reproductive status: young female (5-8 yr), middle-aged female (9-13 yr), older female (14-18 yr), and old female (>19 yr). We estimated these age classes based on relative size, nipple length, and general marks of aging, such as wrinkled skin on the face and the neck, saggy skin around the face, and thinning hair.

When we noticed a new infant in a group, we counted it as a birth. We defined infants as individuals $<12$ mo old. We designated an infant as "dead" when we first noticed that it was either dead or no longer present in a group (since infants cannot survive by themselves).

\section{Data Collection}

We collected demographic data from November 2016 to May 2018, by recording information on group composition and membership daily. All adult macaques were well habituated to human presence and were individually recognizable using natural markings such as face characteristics (color, scars, wrinkles), relative body size, and nipple color and size. We collected behavioral data on macaque-macaque agonistic interactions, human-macaque interactions, and macaque foraging on natural and anthropogenic food for 11 mo between July 2017 and May 2018. MA, RS, and four other field assistants collected 10-min focal animal sampling on all adult macaques (Altmann

Table I Group compositions of two groups of bonnet macaques (Macaca radiata) in Thenmala, Southern India, between 2017 and 2018

\begin{tabular}{llll}
\hline & Age & \multicolumn{2}{l}{ Group } \\
\cline { 3 - 4 } & & LG & SG \\
\hline Young adult females & $5-8$ & 6 & 6 \\
Middle-aged females & $9-13$ & 9 & 7 \\
Older females & $14-18$ & 5 & 1 \\
Old females & $>19$ & 1 & 1 \\
Adult males & $>7$ & $26-36$ & $10-12$ \\
Subadult females & $4-5$ & $1-2$ & $3-5$ \\
Subadult males & $4-6$ & $6-13$ & $2-3$ \\
Juveniles (both sexes) & $1-3$ & $7-18$ & 6 \\
Infant females & $<1$ & 15 & 8 \\
Infant males & $<1$ & 16 & 11 \\
\hline
\end{tabular}


1974). The observers reached interobserver reliability in focal sampling prior to commencing data collection, with MA as the standard (range of Cohen's K: 0.830.96). On each day, we followed a predetermined, randomized sequence to find and sample the focal animals, aiming to obtain two 10-min focal samples of each individual each week, one in the morning and one in the afternoon.

During focal sessions, we recorded dyadic agonistic interactions (aggressive interactions and submissive signaling; Boccia et al. 1988; Silk et al. 1981a) continuously. We also collected human-macaque interactions continuously, i.e., behaviors initiated by a focal animal toward one or more humans (e.g., approach, contact and noncontact aggression, begging for food), or by one or more human(s) toward a focal animal (e.g., approach, aggression, provisioning with food, taunting) that elicited a response from the recipient. Finally, they also recorded the focal animals' main activity (resting/moving/socializing/foraging on natural or anthropogenic food) once every $2 \mathrm{~min}$ in the form of point-time scans within the focal sessions (Altmann 1974). We provide further details and definitions of protocols, behaviors, and definitions/criteria used to classify anthropogenic and natural foods in our previous publications (Balasubramaniam et al. 2020a; Kaburu et al. 2019a, b; Marty et al. 2019a, b).

\section{Dominance Rank of Mothers}

From all dyadic agonistic interactions with a clear winner and loser, we calculated the dominance ranks of individuals of each group, using the Perc package (Fujii et al. 2015) in R (R Core Team 2020). To control for group size, we standardized the ordinal ranks for each group and sex to create a rank index, hereafter "percentile rank," that ranged between 0 (lowest ranked individual) and 1 (highest ranked individual) (as in Balasubramaniam et al. 2020a).

\section{Anthropogenic Factors: Human-Macaque Interactions and Foraging on Anthropogenic Food}

From the continuously collected focal data, we calculated the overall frequency of interactions with humans relative to the total observation time for each female. From the point time samples of macaques' main activity, we calculated the use of anthropogenic food for each individual as the number of point-time samples in which they foraged on anthropogenic food divided by the total number of point-time samples they foraged on either natural or anthropogenic food (Balasubramaniam et al. 2020a; Marty et al. 2019b).

\section{Statistical Analysis}

We first ran diagnostic tests to confirm that the age and dominance rank of the females correlated with parity. To determine the relationship between macaque age class and parity, we ran a chi-squared test. To determine the effect of rank on parity, we ran a generalized linear mixed model (GLMM) with a binomial function, using the lme 4 package in R (Bates et al. 2015; R Core Team 2020). The outcome variable was the parity of the female coded as " 0 " for primiparous, and " 1 " for multiparious. As predictors, we included dominance rank percentile as a main effect and group ID as a random effect. 
To test our predictions, we used a Cox proportional hazards model to model survival to $1 \mathrm{yr}$. We allowed different baselines for the $2 \mathrm{yr}$. This approach allowed the year effects to vary in the model while making no attempt to statistically quantify this variation (as $2 \mathrm{yr}$ is not enough to do this reliably). We used sex of the infant, anthropogenic factors (i.e., human-macaque interactions and preference for anthropogenic food), and demographic and social characteristics of the mother (choices based on the results of the above diagnostic tests) in the model. We also included group ID as a factor in the model to account for potential intergroup differences in our outcome. We used likelihood ratio tests (LRTs) to compare the full model with one without each predictor variable in turn, to assess the effects of each predictor variable while accounting for the effects of all other predictor variables.

We performed all analyses using the statistical software R (Bates et al. 2015; R Core Team 2020). We fitted the Cox proportional hazards model using survival $\mathrm{R}$ package (Therneau 2011) and calculated the variance inflation factors (VIFs) using the rms package (Harrell 2020).

\section{Ethical Note}

All data were collected from habituated, free-living animals without interfering with their activities. We conducted the study outside protected areas and complied with Indian laws and those of the Kerala Forest Department. The protocols were approved by the Forest Department in Thenmala at the time the field research was conducted and reviewed and approved by the University of California Davis Institutional Animal Care and Use Committee. The authors declare that they have no conflict of interest.

Data Availability The datasets analyzed during the current study are available from the corresponding author on reasonable request.

\section{Results}

\section{General Patterns of Infant Mortality}

During two birth seasons (2017-2018), 34 females gave birth to 50 infants $(N=24$ females and $N=26$ males; Table II). Ten infants were born to primiparous females and 40 infants were born to multiparous females. There were 31 births in LG group and 19 in SG group. Fourteen infants $(41 \%)$ died or disappeared during the study (Table II).

\section{Diagnostic Tests}

As we predicted, females' age was strongly associated with parity $\left(\chi^{2}(2)=29.2, P<\right.$ 0.01). This informed our decision not to include parity and age in the same Cox hazards model (due to the strong overlap of the variable categories), and only use parity. The GLMM showed that dominance rank percentile also strongly predicted parity: high- 
Table II Female characteristics, births, survival and causes of infant death in two groups of bonnet macaques (Macaca radiata) between 2017 and 2018 in Thenmala, Southern India

\begin{tabular}{|c|c|c|c|c|c|c|c|c|}
\hline Mother & Infant & Group & Year & Age & Rank & Parity & Infant death & Cause of death \\
\hline $\mathrm{Bl}$ & Male & LG & 2017 & Older & 1 & Multiparous & No & \\
\hline $\mathrm{Bl}$ & Male & LG & 2018 & Older & 1 & Multiparous & No & \\
\hline $\mathrm{Be}$ & Male & LG & 2017 & Young & 3 & Multiparous & No & \\
\hline $\mathrm{Be}$ & Female & LG & 2018 & Young & 3 & Multiparous & No & \\
\hline Ts & Male & LG & 2017 & Older & 4 & Multiparous & No & \\
\hline Ts & Male & LG & 2018 & Older & 4 & Multiparous & No & \\
\hline $\mathrm{Yd}$ & Female & LG & 2017 & Middle & 5 & Multiparous & No & \\
\hline $\mathrm{Yd}$ & Female & LG & 2018 & Middle & 5 & Multiparous & No & \\
\hline $\mathrm{Mz}$ & Male & LG & 2018 & Middle & 6 & Multiparous & Yes & Left behind \\
\hline Jn & Male & LG & 2017 & Middle & 7 & Multiparous & No & \\
\hline $\mathrm{Jn}$ & Male & LG & 2018 & Middle & 7 & Multiparous & No & \\
\hline $\mathrm{K} 1$ & Male & LG & 2017 & Middle & 8 & Multiparous & Yes & Hit by car \\
\hline $\mathrm{Kl}$ & Female & LG & 2018 & Middle & 8 & Multiparous & No & \\
\hline $\mathrm{Sc}$ & Male & LG & 2017 & Older & 9 & Multiparous & No & \\
\hline $\mathrm{Km}$ & Female & LG & 2017 & Middle & 10 & Multiparous & Yes & Hit by car \\
\hline $\mathrm{Km}$ & Female & LG & 2018 & Middle & 10 & Multiparous & No & \\
\hline $\mathrm{Zr}$ & Female & LG & 2017 & Young & 11 & Multiparous & No & \\
\hline $\mathrm{Mr}$ & Female & LG & 2017 & Middle & 12 & Multiparous & No & \\
\hline $\mathrm{Te}$ & Male & LG & 2017 & Middle & 13 & Multiparous & No & \\
\hline $\mathrm{Te}$ & Female & LG & 2018 & Middle & 13 & Multiparous & No & \\
\hline $\mathrm{Ma}$ & Male & LG & 2017 & Middle & 14 & Multiparous & No & \\
\hline Ma & Male & LG & 2018 & Middle & 14 & Multiparous & Yes & Disappeared \\
\hline Ty & Female & LG & 2017 & Young & 15 & Primiparous & Yes & Electrocuted \\
\hline $\mathrm{Pk}$ & Male & LG & 2018 & Middle & 16 & Multiparous & No & \\
\hline $\mathrm{Bu}$ & Female & LG & 2017 & Older & 17 & Multiparous & No & \\
\hline $\mathrm{Bu}$ & Male & LG & 2018 & Older & 17 & Multiparous & No & \\
\hline $\mathrm{Nv}$ & Female & LG & 2018 & Young & 18 & Primiparous & No & \\
\hline In & Female & LG & 2017 & Young & 19 & Primiparous & No & \\
\hline In & Female & LG & 2018 & Young & 19 & Multiparous & No & \\
\hline Fn & Female & LG & 2018 & Older & 20 & Multiparous & No & \\
\hline Fy & Male & LG & 2018 & Young & 22 & Primiparous & No & \\
\hline $\operatorname{Tr}$ & Female & SG & 2017 & Middle & 1 & Multiparous & No & \\
\hline $\operatorname{Tr}$ & Male & SG & 2018 & Middle & 1 & Multiparous & Yes & Died within $24 \mathrm{~h}$ of birth \\
\hline Le & Female & SG & 2017 & Older & 2 & Multiparous & No & \\
\hline $\mathrm{Bn}$ & Male & SG & 2017 & Young & 3 & Primiparous & Yes & Stillbirth \\
\hline $\mathrm{Bn}$ & Female & SG & 2018 & Young & 3 & Multiparous & No & \\
\hline $\mathrm{Zm}$ & Male & SG & 2017 & Middle & 4 & Multiparous & No & \\
\hline Ry & Female & SG & 2017 & Middle & 5 & Multiparous & Yes & Disappeared \\
\hline Ry & Male & SG & 2018 & Middle & 5 & Multiparous & No & \\
\hline $\mathrm{Sp}$ & Female & SG & 2017 & Middle & 6 & Multiparous & No & \\
\hline $\mathrm{Sp}$ & Female & $\mathrm{SG}$ & 2018 & Middle & 6 & Multiparous & No & \\
\hline
\end{tabular}


Table II (continued)

\begin{tabular}{lllllllll}
\hline Mother & Infant & Group & Year & Age & Rank & Parity & Infant death & Cause of death \\
\hline Ln & Male & SG & 2017 & Middle & 7 & Multiparous & Yes & Hit by car \\
Ln & Male & SG & 2018 & Middle & 7 & Multiparous & Yes & Electrocuted \\
Pn & Female & SG & 2018 & Young & 8 & Primiparous & Yes & Unknown \\
Ax & Male & SG & 2018 & Young & 10 & Primiparous & Yes & Unknown \\
St & Male & SG & 2018 & Young & 11 & Primiparous & Yes & Unknown \\
Py & Male & SG & 2017 & Young & 12 & Primiparous & Yes & Died within 24 h of birth \\
Rs & Female & SG & 2017 & Young & 13 & Primiparous & No & \\
Vv & Male & SG & 2018 & Middle & 14 & Multiparous & No & \\
Dt & Male & SG & 2018 & Middle & 15 & Multiparous & No & \\
\hline
\end{tabular}

ranking females were more likely to be multiparous than low-ranking females ( $\beta=$ $4.90, z=2.62, P=0.01)$.

Nevertheless, we still included parity and rank in the same Cox hazards model; VIF values for these variables (1.9 for both rank and parity) suggested that their collinearity was not an issue. We could not calculate the VIF for age in a model including parity because parameter estimates for the model did not converge, presumably because of the strong association between age and parity.

\section{Infant Survival Relative to Mother's Parity, Rank, Infant Sex, and Anthropogenic Factors}

Our proportional hazards model (LRT: $15.9, \mathrm{df}=6, P=0.01$; Wald: $13.3, \mathrm{df}=6, P=$ 0.04 ; score: $17.1, \mathrm{df}=6, P=0.01$; Table III) showed that parity significantly predicted infant survival: infants of primiparous mothers had higher mortality than those of multiparous mothers (LRT: 9.01, $\mathrm{df}=1, P=0.01$; Figs. 1 and 2). We also found that male infants had lower survival than female infants (LRT: 4.37, $\mathrm{df}=1, P=0.04$; Figs. 1 and 2). In contrast, rank was not a significant predictor of mortality. We found no significant effect of human-macaque interactions or foraging on anthropogenic food on infant survival. Finally, group ID had no significant effect on survival.

\section{Discussion}

Consistent with findings in other primate species, we found that parity strongly influenced infant survival, and that infants of multiparous mothers were three times more likely to survive than those of primiparous mothers. This implies a difference in the quality of maternal care between primiparous and multiparous mothers, which may be related to their experience. Moreover, younger mothers are more limited in the energy they can allocate to reproduction, because they may not have stopped growing (Bercovitch et al. 1998; Clutton-Brock 1984; Descamps et al. 2008; Hinde 2007; Hinde and Capitanio 2010; Setchell et al. 2002). The relationship between parity and infant survival may be linked to different energetic needs in young and old females. Younger 
Table III Analysis of deviance table for the proportional hazard model for infant survival in bonnet macaques (Macaca radiata) between 2017 and 2018 in Thenmala, Southern India

\begin{tabular}{llll}
\hline Term & Chi-squared statistic & df & $P$-value \\
\hline Parity & 9.01 & 1 & 0.01 \\
Infant sex & 4.37 & 1 & 0.04 \\
Female dominance rank & 1.32 & 1 & 0.25 \\
Human-macaque interactions & 0.03 & 1 & 0.86 \\
Foraging on anthropogenic food & 0.04 & 1 & 0.85 \\
Group & 1.95 & 1 & 0.16 \\
\hline
\end{tabular}

females may also be less able to carry their offspring everywhere because the females are smaller than older females. As alloparental interactions are rare in bonnet macaques (Silk 1990; Simonds 1974), first-time mothers may not receive much help with care for their infants. With subsequent births, however, the quality of their maternal care may increase (Maestripieri and Carroll 1998).

We also found that male infants were more likely to die than female infants. Greater male mortality in infancy has also been reported in captive rhesus macaques and may

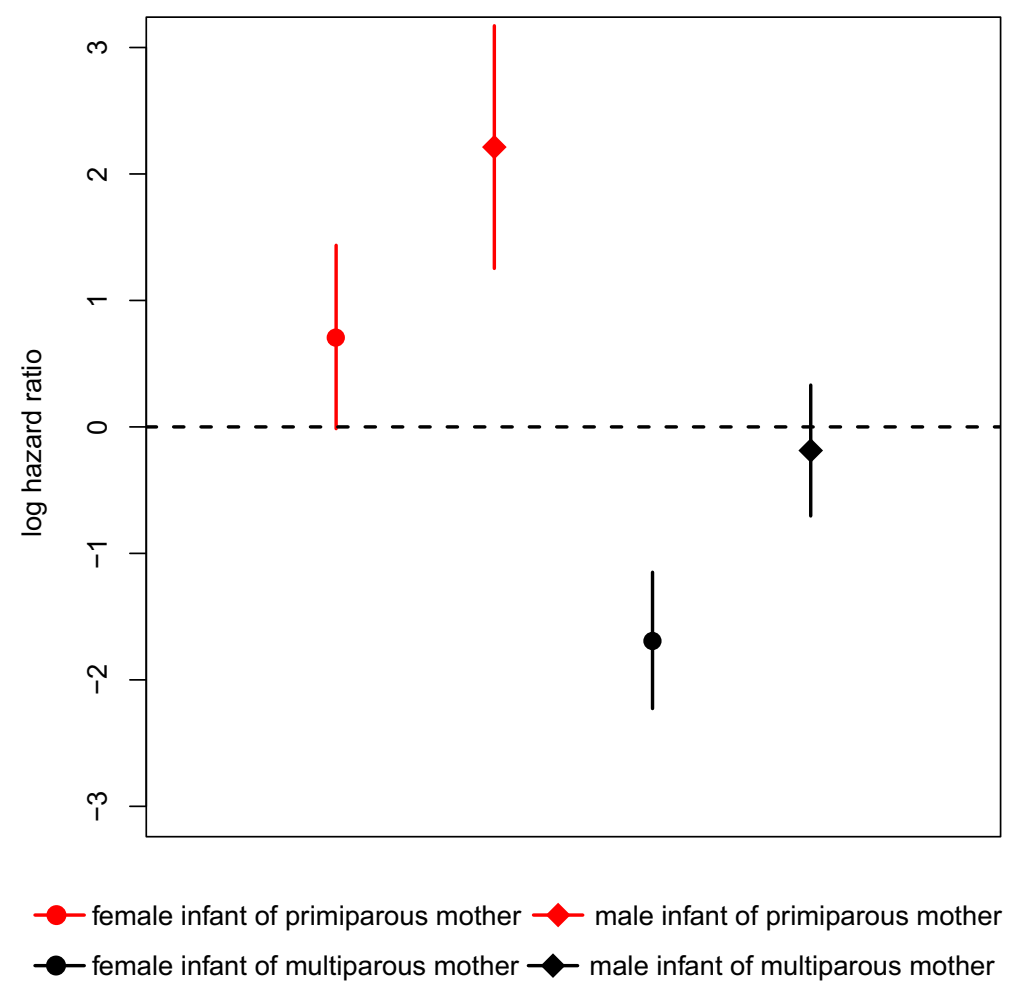

Fig. 1 Relative hazard estimates with the corresponding standard errors based on the proportional hazards model on a logarithmic scale in bonnet macaques (Macaca radiata) between 2017 and 2018 in Thenmala, Southern India. Exponentiating the estimates yields hazard ratio estimates. The dashed horizontal line corresponds to the mean covariate values in the sample. 


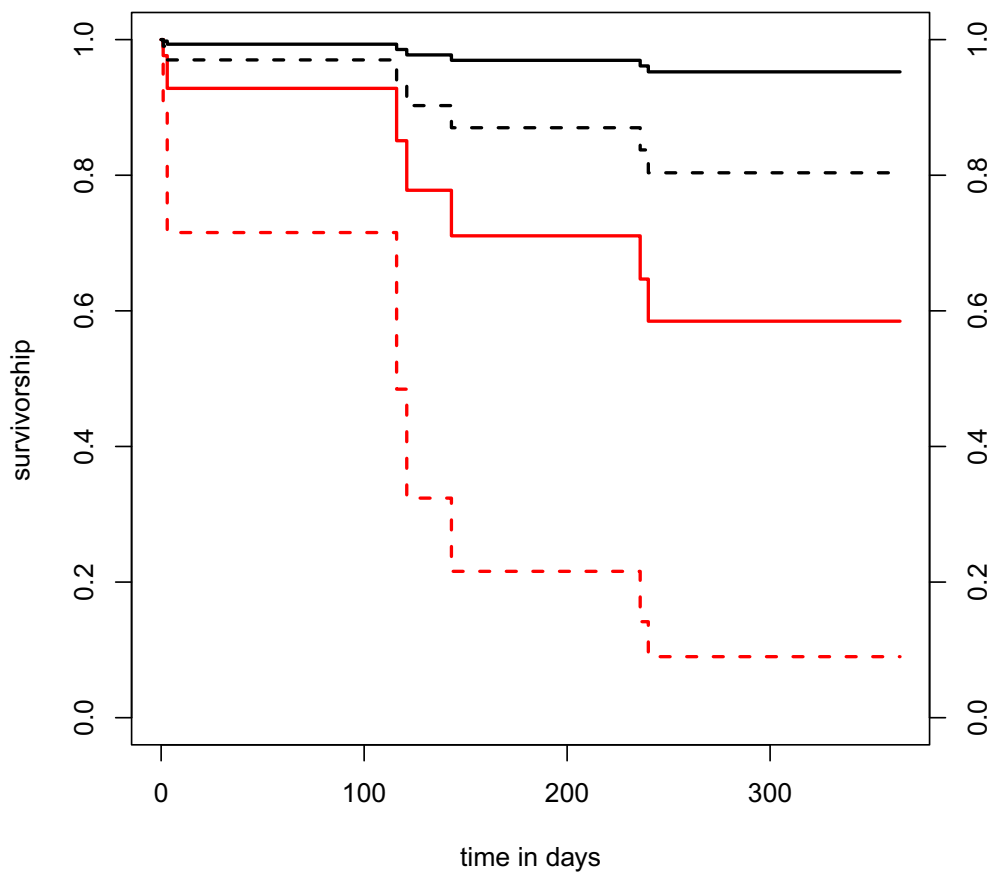

— female infant of primiparous mother - - male infant of primiparous mother

- female infant of multiparous mother - - male infant of multiparous mother

Fig. 2 Survivorship curves corresponding to the proportional hazards model in bonnet macaques (Macaca radiata) between 2017 and 2018 in Thenmala, Southern India.

be related to male infants needing more maternal investment than female infants but not receiving sufficient maternal investment to thrive (Hinde 2007). A similar pattern has also been documented in humans (Drevenstedt et al. 2008). As a proximate explanation, higher mortality of infant males may be a consequence of infant temperament. For instance, in squirrel monkeys (Saimiri sciureus), rhesus macaques, and patas monkeys (Erythrocebus patas), male infants are more exploratory, and engage in play behavior more than female infants (Biben 1986; Brown and Dixson 2000; Rowell and Chism 1986). Such behaviors may bear particular risks in anthropogenic environments, where exploring infants may be more exposed to roads, vehicles, electric wires, and interactions with humans and feral dogs. Our results differ from earlier work on captive bonnet macaques, which did not show such sex differences in infant mortality (Silk et al. 1981b). Here, such a result may be a consequence of living in wild, and particularly human-impacted environments, where macaques face more variable, sometimes unpredictable or risky socioecological conditions, like differential access to natural and anthropogenic food, male migration, encounters with humans and other urban animal predators, as well as exposure to traffic, sharp fences and substrates, and electric wires.

We found no evidence that having a higher rank affording greater infant survival. Studies that do show a correlation between rank and infant survival suggest that this effect may be more pronounced under certain conditions, such as low or no predation 
pressure and/or rank-related effects on access to food (e.g., olive baboons: Packer et al. 1995; chimpanzees: Pusey et al. 1997; vervet monkeys: Cheney and Seyfarth 1987; long-tailed macaques Macaca fascicularis: van Noordwijk and van Schaik 1987). At our study site, however, bonnet macaques coexist with feral dogs, and occasionally (in parts of their home range) with leopards or Indian rock pythons, which are natural predators of the macaques (Coss et al. 2002). They also experience potentially stressful interactions with humans and anthropogenic environments and coping with this may require greater intragroup cohesion and social tolerance (Balasubramaniam et al. 2020a; Marechal et al. 2011).

In many primate species (including bonnet macaques), dominance rank offers better access to preferred food items (e.g., Barton 1993; Chancellor and Isbell 2009; Koenig 2000; Marty et al. 2019b; Whitten 1983). Although dominance rank may generally impact macaques' access to anthropogenic food (Marty et al. 2019b), in our population rank was not correlated to access to anthropogenic food resources (McCowan, unpubl. data). This may have been because both natural and anthropogenic food was abundant both spatially and temporally throughout the study. Under such ecological conditions of moderate predation pressure, high human impact, and greater abundance of food, dominance rank does not have a strong impact on female fitness and/or infant survival.

We found that many infant deaths were side effects of living in an anthropogenic environment, and multiple infants $(N=5)$ died from being hit by cars or electrocuted. Anthropogenically modified habitats can present challenging, stressful environments for primates (McKinney 2015; McKinney and Dore 2018). Mothers that are relatively naïve to infant behavior might find it more difficult to combine infant care and vigilance while walking on the roads, passing bridges, or climbing poles with electrical wires than more experienced mothers. Indeed, previous studies on bonnet macaque populations in anthropogenic habitats showed that the survival of immature individuals was markedly lower than those in forest habitats (Singh and Rao 2004). In this light, a comparative study of the predictors of female reproductive success and infant survival among bonnet macaques living in human-impacted environments (like our study population) to macaques in relatively unperturbed forest habitats would be a logical next step.

The anthropogenic causes of infant deaths contrast with our finding that the anthropogenic exposure of individual females, specifically the frequencies of interactions with humans and time spent foraging on anthropogenic foods, had no effect on infant survival. One reason for this discrepancy may be that, in the short term, the costs females incurred when interacting with humans (e.g., injuries, stress, illness) may have been offset by the benefits of access to high-energy, abundantly available anthropogenic food (Marty et al. 2019b). In other words, these two anthropogenic factorsinteractions with humans and foraging on anthropogenic food - may have negated each other's impact on female fitness and hence infant survival. A second reason could be that frequencies of direct interactions with humans, as measured and evaluated here, were uniformly and relatively (to other macaque populations) low in our study population, possibly too low to impact interindividual differences in females' fitness (Balasubramaniam et al. 2020b). Finally, it is conceivable that the impact of interactions with humans and foraging on human foods on offspring survival may be more discernible 1) over longer time frames that affect chronic health and fitness outcomes, or through 2) comparative studies of other populations facing varying degrees of 
anthropogenic environmental impact. The short time frame of this study, which covered just two birth seasons, was one of its limitations.

Our study has implications for the conservation of bonnet macaques. Generally, understanding socioecological factors that affect reproduction and survival is important in increasing our ability to effectively manage populations threatened with extinction, even when models are built in contexts where the study species is not threatened. The fact that naïve mothers in particular may be more vulnerable to losing offspring in unpredictable anthropogenic environments suggests that the Thenmala bonnet macaque population remains vulnerable. As a species, bonnet macaques are restricted to peninsular Southern India, where an expanding human population is associated with a decreasing population trend (Sinha 2013; Sinha and Mukhopadhyay 2013). It will therefore be important to design and implement cost-effective tools for monitoring population health; gain more insights into the mortality of bonnet macaques; and more generally better distinguish the effects of social, ecological, and anthropological stress on reproduction and infant survival.

Acknowledgments We thank the Kerala Forest Department and the Indian Institute of Science Education and Research (IISER) Thiruvananthapuram for facilitating our research in Thenmala. We thank Dr. Hema Somanathan and her research group at IISER Thiruvananthapuram for providing access to their field station and for assisting with logistics related to the commencement of fieldwork. We are grateful to Pooja Dongre, Mohammed Ismail, Megha Majoe, Alvaro Sobrino, and Menno van Berkel for their assistance with data collection. We thank Prof. Mewa Singh for his constructive comments and suggestions to improve this manuscript. Finally, we appreciate the comments and suggestions by the editor and two anonymous reviewers to improve the manuscript. This work was supported by the American National Science Foundation Coupled Natural and Human Systems grant (NSF-CNH \#1518555) awarded to the PI Dr. Brenda McCowan and by National Science Centre Harmonia grant (2018/30/M/NZ8/00025) awarded to Dr. Małgorzata Arlet.

Author Contributions MEA formulated the idea; BM, BB, KNB, PRM, SSKK, and EBM developed the methodology. MEA, RS, and KNB conducted fieldwork. MEA, AK, and KNB performed statistical analyses. MEA and KNB wrote the manuscript, and the other authors provided editorial advice.

Open Access This article is licensed under a Creative Commons Attribution 4.0 International License, which permits use, sharing, adaptation, distribution and reproduction in any medium or format, as long as you give appropriate credit to the original author(s) and the source, provide a link to the Creative Commons licence, and indicate if changes were made. The images or other third party material in this article are included in the article's Creative Commons licence, unless indicated otherwise in a credit line to the material. If material is not included in the article's Creative Commons licence and your intended use is not permitted by statutory regulation or exceeds the permitted use, you will need to obtain permission directly from the copyright holder. To view a copy of this licence, visit http://creativecommons.org/licenses/by/4.0/.

\section{References}

Abello, M. T., \& Colell, M. (2006). Analysis of factors that affect maternal behavior and breeding success in great apes in captivity. International Zoo Yearbook, 40, 323-340.

Altmann, J. (1974). Observational study of behavior: sampling methods. Behavior, 49, 227-267.

Altmann, J., \& Alberts, S. C. (2005). Growth rates in a wild primate population: ecological influences and maternal effects. Behavioral Ecology and Sociobiology, 57, 490-501. 
Arlet, M. E., Isbell, L. A., Molleman, F., Kaasik, A., Chancellor, R. L., et al (2014). Maternal investment and infant survival in gray-cheeked mangabeys (Lophocebus albigena). International Journal of Primatology, $35,476-490$.

Arlet, M. E., Veromann-Jürgenson, L. L., Isbell, L. A., Mänd, R., \& Lemasson, A. (2019). Maternal care in free-ranging arboreal grey-cheeked mangabeys (Lophocebus albigena johnstoni) in Kibale National Park, Uganda. Folia Primatologica. https://doi.org/10.1159/000499656.

Balasubramaniam, K. N., Marty, P. R., Arlet, M. E., Beisner, B. A., Kaburu, S. K. K., et al (2020a). Impact of anthropogenic factors on affiliative behaviors among bonnet macaques. American Journal of Physical Anthropology, 171, 704-717.

Balasubramaniam, K. N., Marty, P. R., Samartino, S., Sobrino, A., Saha, R., et al. (2020b). Impact of individual demographic and social factors on human-wildlife interactions: a comparative study of three macaque species. Scientific Reports, 10, 21991. https://doi.org/10.1038/s41598-020-78881-3.

Barton, R. A. (1993). Sociospatial mechanisms of feeding competition in female olive baboons, Papio anubis. Animal Behavior, 46, 791-802.

Bates, D., Maechler, M., Bolker, B., \& Walker, S. (2015). Fitting linear mixed effects models using lme4. Journal of Statistical Software, 67, 1-48.

Bercovitch, F. B., \& Berard, J. D. (1993). Life history costs and consequences of rapid reproductive maturation in female rhesus macaques. Behavioral Ecology and Sociobiology, 32, 103-109.

Bercovitch, F. B., Lebron, M. R., Martinez, H. S., \& Kessler, M. J. (1998). Primigravidity, body weight, and costs of rearing first offspring in rhesus macaques. American Journal of Primatology, 46, 135-144.

Bercovitch, F. B., Widdig, A., \& Nürnberg, P. (2000). Maternal investment in rhesus macaques (Macaca mulatta): reproductive costs and consequences of raising sons. Behavioral Ecology and Sociobiology, 48, $1-11$.

Biben, M. (1986). Individual and sex-related strategies of wrestling play in captive squirrel monkeys. Ethology, 71, 229-241.

Boccia, M. L., Laudenslager, M., \& Reite, M. (1988). Food distribution, dominance, and aggressive behaviors in bonnet macaques. American Journal of Primatology, 16, 123-130.

Brown, G. R., \& Dixson, A. F. (2000). The development of behavioral sex differences in infant rhesus macaques (Macaca mulatta). Primates, 41, 63-77.

Chancellor, R. L., \& Isbell, L. A. (2009). Food site residence time and female competitive relationship in wild gray-cheeked mangabeys (Lophocebus albigena). Behavioral Ecology and Sociobiology, 63, 1447-1458.

Cheney, D. L., \& Seyfarth, R. M. (1987). The influence of intergroup competition on the survival and reproduction of female vervet monkeys. Behavioral Ecology and Sociobiology, 21, 375-386.

Clutton-Brock, T. H. (1984). Reproductive effort and terminal investment in iteroparous animals. American Naturalist, 123, 212-229.

Coss, R. G., Marks, S., \& Ramakrishnan, U. (2002). Early environment shapes the development of gaze aversion by wild bonnet macaques (Macaca radiata). Primates, 43, 217-222.

Descamps, S., Boutin, S., Berteaux, D., \& Gaillard, J. (2008). Age-specific variation in survival, reproductive success and offspring quality in red squirrels: evidence of senescence. Oikos, 117, 1406-1416.

Dettmer, A. M., Kaburu, S. S., Byers, K. L., Murphy, A. M., Soneson, E., et al (2016). First-time rhesus monkey mothers, and mothers of sons, preferentially engage in face-to-face interactions with their infants. American Journal of Primatology, 78, 238-246.

Drevenstedt, G. L., Crimmins, E. M., Vasunilashorn, S., \& Finch, C. E. (2008). The rise and fall of excess male mortality. Proceedings of the National Academy of Sciences of the United States of America, 105, 5016-5021.

Erinjery, J. J., Kumar, S., Kumara, H. N., Mohan, K., Dhananjaya, T., et al. (2017). Losing its ground: a case study of fast declining populations of a 'least-concern' species, the bonnet macaque (Macaca radiata). PloS ONE. https://doi.org/10.1371/journal.pone.0182140.

Fairbanks, L. A. (1990). Reciprocal benefits of allomothering for female vervet monkeys. Animal Behavior, 40, 553-562.

French, J. A., Pissinatti, A., \& Coimbra-Filho, A. F. (1996). Reproduction in captive lion tamarins (Leontopithecus): Seasonality, infant survival, and sex ratios. American Journal of Primatology, 39, 17-33.

Fuentes, A. (2012). Ethnoprimatology and the anthropology of the human-primate interface. Annual Review of Anthropology, 41, 101-117.

Fujii, K., Jin, J., Shev, A., Beisner, B., McCowan, B., \& Fushing, H. (2015). Perc: Using percolation and conductance to find information flow certainty in a direct network. $R$ Package Version 0.1. Vienna: $\mathrm{R}$ Foundation for Statistical Computing. 
Garcia, C., Lee, P. C., \& Rosetta, L. (2009). Growth in colony living anubis baboon infants and its relationship with maternal activity budgets and reproductive status. American Journal of Physical Anthropology, 138, 123-135.

Harcourt, A. H. (1987). Dominance and fertility among female primates. Journal of Zoology. https://doi.org/ 10.1111/j.1469-7998.1987.tb03721.x.

Harrell, F. E. Jr. (2020). rms: Regression modeling Strategies. R package version 6.1-0.

Hinde, K. (2007). First-time mothers bias milk composition in favor of sons. Current Biology, 17, R958-R959.

Hinde, K. (2009). Richer milk for sons but more milk for daughters: sex-biased investment during lactation varies with maternal life history in rhesus macaques. American Journal of Human Biology, 21, 512-519.

Hinde, K., \& Capitanio, J. P. (2010). Lactational programming? Mother's milk energy predicts infant behavior and temperament and rhesus macaques (Macaca mulatta). American Journal of Primatology, 72, 522-529.

Hrdy, S. B. (1976). Care and exploitation of non-human primate infants by conspecifics other than the mother. In J. S. Rosenblatt, R. A. Hinde, E. Shaw, \& C. Bier (Eds.), Advances in the study of behavior (pp. 101158). New York: Academic Press.

Isbell, L. A., Young, T. P., Jaffe, K. E., Carlson, A. A., \& Chancellor, R. L. (2009). Demography and life histories of sympatric patas monkeys (Erythrocebus patas) and vervets (Cercopithecus aethiops) in Laikipia, Kenya. International Journal of Primatology, 30, 103-124.

Jaman, M. F., \& Huffman, M. A. (2013). The effect of urban and rural habitats and resource type on activity budgets of commensal rhesus macaques (Macaca mulatta) in Bangladesh. Primates, 54, 49-59.

Kaburu, S. S. K., Marty, P. R., Beisner, B., Balasubramaniam, K. N., \& Bliss-Moreau, E. (2019a). Rates of human-macaque interactions affect grooming behavior among urban-dwelling rhesus macaques (Macaca mulatta). American Journal of Physical Anthropology, 168, 92-103.

Kaburu, S. S. K., Beisner, B., Balasubramaniam, K. N., Marty, P. R., Bliss-Moreau, E., et al (2019b). Interactions with humans impose time constraints on urban-dwelling rhesus macaques (Macaca mulatta). Behavior, 1, 1-28.

Kleindorfer, S., \& Wasser, S. K. (2004). Infant handling and mortality in yellow baboons. Behavioral Ecology and Sociobiology, 56, 328-337.

Koenig, A. (2000). Competitive regimes in forest-dwelling Hanuman langur females (Semnopithecus entellus). Behavioral Ecology and Sociobiology, 48, 93-109.

Kumar, R., Radhakrishna, S., \& Sinha, A. (2011). Of least concern? Range extension by rhesus macaques (Macaca mulatta) threatens long-term survival of bonnet macaques (M. radiata) in peninsular India. International Journal of Primatology, 32, 945-959.

Kumara, H. N., Kumar, S., \& Singh, M. (2010). Of how much concern are the 'least concern' species? Distribution and conservation status of bonnet macaques, rhesus macaques and hanuman langurs in Karnataka, India. Primates, 51, 37-42.

Kurita, H., Sugiyama, Y., Ohsawa, H., Hamada, Y., \& Watanabe, T. (2008). Changes in demographic parameters of Macaca fuscata at Takasakiyama in relation to decrease of provisioned foods. International Journal of Primatology, 29, 1189-1202.

Lee, P. C. (1987). Nutrition, fertility and maternal investment in primates. Journal of Zoology, 213, 409-422.

Maestripieri, D., \& Carroll, K. A. (1998). Risk factors for infant abuse and neglect in group-living rhesus monkeys. Psychological Science, 9, 143-145.

Marechal, L., Semple, S., Majolo, B., Qarro, M., Heistermann, M., \& MacLarnon, A. (2011). Impacts of tourism on anxiety and physiological stress levels in wild male Barbary macaques. Biological Conservation, 144, 2188-2193.

Marty, P. R., Beisner, B., Kaburu, S. S. K., Balasubramaniam, K. N., Bliss-Moreau, E., et al (2019a). Time constraints imposed by anthropogenic environments alter social behavior in longtailed macaques. Animal Behavior, 150, 157-165.

Marty, P. R., Balasubramaniam, K. N., Kaburu, S. S. K., Hubbard, J., Beisner, B. A., et al. (2019b). Individuals in urban dwelling primate species face unequal benefits associated with living in an anthropogenic environment. Primates, 61, 249-255.

McKinney, T. (2015). A classification system for describing anthropogenic influence on nonhuman primate populations. American Journal of Primatology, 77, 715-726.

McKinney, T., \& Dore, K. M. (2018). The state of ethnoprimatology: its use and potential in today's primate research. International Journal of Primatology, 39, 730-748.

McLennan, M. R., \& Ganzhorn, J. U. (2017). Nutritional characteristics of wild and cultivated foods for chimpanzees (Pan troglodytes) in agricultural landscapes. International Journal of Primatology, 38, 122-150.

Meaney, M. J., Lozos, E., \& Steward, J. (1990). Infant carrying by nulliparous female vervet monkeys (Cercopithecus aethiops). Journal of Comparative Psychology, 104, 377-381.

Nathan, T. S., \& Kaufman, I. C. (1972). Perinatal observations of mother-infant behavior in the bonnet macaque. The Israel Annals of Psychiatry and Related Disciplines, 10, 245-266. 
Nishida, T., Corp, N., Hamai, M., Hasegawa, T., Hiraiwa-Hasegawa, M., et al (2003). Demography, female life history, and reproductive profiles among the chimpanzees of Mahale. American Journal of Primatology, 59, 99-121.

Oro, D., Genovart, M., Tavecchia, G., Fowler, M. S., \& Martínez-Abraín, A. (2013). Ecological and evolutionary implications of food subsidies from humans. Ecology Letters, 16, 1501-1514.

Ostner, J., Borries, C., Schülke, O., \& Koenig, A. (2005). Sex allocation in a colobine monkey. Ethology, 111, 924-939.

Packer, C., Collins, D. A., Sindwimwo, A., \& Goodall, J. (1995). Reproductive constraints on aggressive competition in female baboons. Nature, 373, 60-63.

Pusey, A. E. (2012). Magnitude and sources of variation in female reproductive performance. In J. C. Mitani, J. Call, P. M. Kappeler, R. A. Palombit, \& J. B. Silk (Eds.), The evolution of primate societies (pp. 143166). Chicago: University of Chicago Press.

Pusey, A., Williams, J., \& Goodall, J. (1997). The influence of dominance rank on the reproductive success of female chimpanzees. Science, 227, 828-831.

Rahaman, H., \& Parthasarathy, M. D. (1969). Studies on the social behavior of bonnet monkeys. Primates, 10, $149-162$.

R Core Team (2020). R: A language and environment for statistical computing. R Foundation for Statistical Computing, Vienna, Austria. https://www.Rproject.org/.

Riley, E. P., Tolbert, B., \& Farida, W. R. (2013). Nutritional content explains the attractiveness of cacao to crop raiding Tonkean macaques. Current Zoology, 59, 160-169.

Robbins, A. W., Robbins, M. M., \& Fawcett, K. (2007). Maternal investment of the Virunga mountain gorillas. Ethology, 113, 235-245.

Rowell, T. E., \& Chism, J. (1986). The ontogeny of sex differences in the behavior of patas monkeys. International Journal of Primatology, 7, 83-107.

Sapolsky, R. M., \& Share, L. J. (2004). A Pacific culture among wild baboons: its emergence and transmission. PLoS Biology, 2, e106. https://doi.org/10.1371/journal.pbio.0020106.

Schino, G., \& Troisi, A. (2005). Neonatal abandonment in Japanese macaques. American Journal of Physical Anthropology, 126, 447-452.

Setchell, J. M., Lee, P. C., Wickings, E. J., \& Dixson, A. F. (2002). Reproductive parameters and maternal investment in mandrills (Mandrillus sphinx). International Journal of Primatology, 23, 51-68.

Silk, J. B. (1990). Sources of variation in interbirth intervals among captive bonnet macaques (Macaca radiata). American Journal of Physical Anthropology, 82, 213-230.

Silk, J. B. (1999). Why are infants so attractive to others? The form and function of infant handling in bonnet macaques. Animal Behavior, 57, 1021-1032.

Silk, J. B., Samuels, A., \& Rodman, P. S. (1981a). The influence of kinship, rank, and sex on affiliation and aggression between adult female and immature bonnet macaques (Macaca radiata). Behavior, 78, 111-137.

Silk, J. B., Clark-Wheatley, C. B., Rodman, P. S., \& Samuels, A. (1981b). Differential reproductive success and facultative adjustment of sex ratios among captive female bonnet macaques (Macaca radiata). Animal Behavior, 29, 1106-1120.

Simonds, P. E. (1965). The bonnet macaque in South India. In Primate behavior: Field studies of monkeys and apes. New York: Holt, Rinehart \& Winston.

Simonds, P. E. (1974). Sex differences in bonnet macaque networks and social structure. Archives of Sexual Behavior, 3, 151-166.

Singh, M., \& Rao, N. R. (2004). Population dynamics and conservation of commensal bonnet macaques. International Journal of Primatology, 25, 847-859.

Singh, M., Prakash, P., \& Pirta, R. S. (1980). Changing patterns of behavior during the early stages of bonnet monkey (Macaca radiata). Proceedings of the Indian Academy of Sciences (Animal Sciences), 89, 101-108.

Singh, M., Akram, N., \& Pirta, R. S. (1984). Evolution of demographic patterns in the bonnet monkey Macaca radiata. In M. L. Roonwal, S. M. Mohnot, \& N. S. Rathore (Eds.), Current primate researches (pp. 7-16). Jodhpur: Zoology Department, Jodhpur University.

Singh, M., Erinjery, J. J., Kavana, T. S., Roy, K., \& Singh, M. (2011). Drastic population decline and conservation prospects of roadside dark-bellied bonnet macaques (Macaca radiata radiata) of southern India. Primates, 52, 149-154.

Sinha, A. (2001). The monkey in the town's commons: a natural history of the Indian bonnet macaque. NIAS Report R2-2001

Sinha, A. (2013). Bonnet macaque Macaca radiata. In A. J. T. Johnsingh \& N. Manjrekar (Eds.), Mammals of South Asia, volume one (pp. 148-169). Hyderabad: Universities Press.

Sinha, A., \& Mukhopadhyay, K. (2013). The monkey in the town's commons, revisited: An anthropogenic history of the Indian bonnet macaque. In S. Radhakrishna, M. A. Huffman, \& A. Sinha (Eds.), The 
Macaque connection: Cooperation and conflict between humans and macaques (pp. 187-208). New York: Springer Science+Business Media.

Sterck, E. H. M., Watts, D. P., \& Van Schaik, C. P. (1997). The evolution of female social relationships in nonhuman primates. Behavioral Ecology and Sociobiology, 41, 291-309.

Strum, S. C., \& Western, J. D. (1982). Variation in fecundity with age and environment in olive baboons (Papio anubis). American Journal of Primatology, 3, 61-76.

Sugiyama, Y., Kurita, H., Matsui, T., Kimoto, S., \& Egawa, J. (2014). Congenital malformations in Japanese macaques (Macaca fuscata) at Takasakiyama. Primates, 55, 303-311.

Therneau, T. (2011). Survival: Survival analysis, including penalised likelihood. Original Splus- $>$ R port by Thomas Lumley. R Package Version 2.36-10.

van Noordwijk, M. A. (2012). From maternal investment to lifetime maternal care. In J. C. Mitani, J. Call, P. M. Kappeler, R. A. Palombit, \& J. B. Silk. The evolution of primate societies (pp. 321-342). Chicago: University of Chicago Press.

van Noordwijk, M. A., \& van Schaik, C. P. (1987). Competition among female long-tailed macaques, Macaca fascicularis. Animal Behavior, 35, 577-589.

van Noordwijk, M. A., \& van Schaik, C. P. (1999). The effects of dominance rank and group size on female lifetime reproductive success in wild long-tailed macaques, Macaca fascicularis. Primates, 40, 105-130.

Warren, Y., Higham, J. P., Maclarnon, A. M., \& Ross, C. (2011). Crop-raiding and commensalism in olive baboons: The costs and benefits of living with humans. In V. Sommer \& C. Ross (Eds.), Primates of Gashaka (pp. 307-332). New York: Springer Science+Business Media.

Wasser, S. K., Norton, G. W., Kleindorfer, S., \& Rhine, R. J. (2004). Population trend alters the effects of maternal dominance rank on lifetime reproductive success in yellow baboons (Papio cynocephalus). Behavioral Ecology and Sociobiology, 56, 338-345.

Whitten, P. L. (1983). Diet and dominance among female vervet monkeys (Cercopithecus aethiops). American Journal of Primatology, 5, 139-159.

\section{Affiliations}

\section{Małgorzata E. Arlet ${ }^{1} \cdot$ Krishna N. Balasubramaniam ${ }^{2} \cdot$ Rajarshi Saha $^{1} \cdot$ Brianne Beisner ${ }^{2,3}$. Pascal R. Marty ${ }^{2}$ - Stefano S. K. Kaburu ${ }^{4}$. Eliza Bliss-Moreau ${ }^{5}$. Ants Kaasik ${ }^{6}$. Ullasa Kodandaramaiah ${ }^{7}$. Brenda McCowan ${ }^{2,3}$}

1 Institute of Human Biology and Evolution, Faculty of Biology, Adam Mickiewicz University, Poznań, Poland

2 Department of Population Health \& Reproduction, School of Veterinary Medicine, University of California, Davis, Davis, CA, USA

3 California National Primate Research Center, University of California, Davis, Davis, CA, USA

4 Department of Biomedical Science \& Physiology, Faculty of Science \& Engineering, University of Wolverhampton, Wolverhampton, UK

5 Department of Psychology, University of California, Davis, Davis, CA, USA

6 Department of Zoology, Institute of Ecology and Earth Sciences, University of Tartu, Tartu, Estonia

7 IISER-TVM Centre for Research and Education in Ecology and Evolution (ICREEE), School of Biology, Indian Institute of Science Education and Research Thiruvananthapuram, Vithura, Thiruvananthapuram, India 